\title{
Promoting Community Participation in Peri - Urban Infrastructures
}

\author{
Jonida Meniku \\ Faculty of Architecture and Urbanism, Polytechnic University of Tirana, Tirana, Albania
}

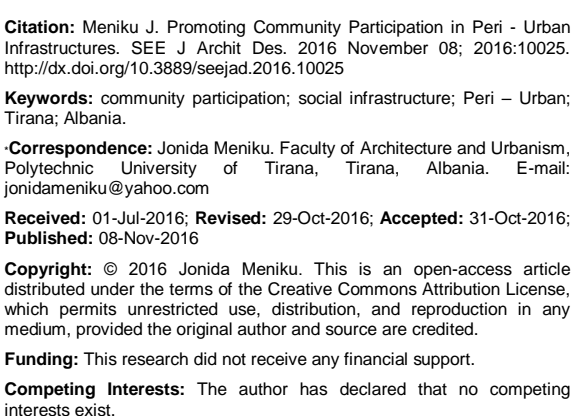

Citation: Meniku J. Promoting Community Participation in Peri - Urban Infrastructures. SEE J Archit Des. 2016 November 08; 2016:10025. ttp./dx.doi.org/10.3889/seejad 2016.10025

Keywords: community participation; social infrastructure; Peri - Urban Tirana; Albania.

Correspondence: Jonida Meniku. Faculty of Architecture and Urbanism Polytechnic University of Tirana, Tirana, Albania. E-mail: jonidameniku@yahoo.com

Received: 01-Jul-2016; Revised: 29-Oct-2016; Accepted: 31-Oct-2016; Published: 08-Nov-2016

Copyright: ๑ 2016 Jonida Meniku. This is an open-access article distributed under the terms of the Creative Commons Attribution License, which permits unrestricted use, distribution, and reproduction in any
medium, provided the original author and source are credited. Funding: This research did not receive any financial support. Competing Interests: The author has declared that no competing interests exist.

\begin{abstract}
AIM: The aim of this research is to examine the importance of community participation in education and social infrastructure in Peri - Urban of Tirana city.

MATERIAL AND METHODS: This research states that "involvement of community" is a direct response to giving the community a voice in shaping their future environment to promote urban regeneration in combination with the respecting of the principle of sustainability.

RESULTS: This rich picture of community participation and urban planning brings an improver's eye to the real issue on the ground, focused mainly on the guidelines set by the European Union. The goal of the project participation which generates public space, beyond the values that carry on improving the quality of life for the citizens - can illustrate how urban regeneration projects may have a huge impact on the entire city life. The result is to create an area which improves profits and a good lifestyle; re conceptualization of investment as an investment in urban infrastructure, an investment that can have a large impact even with a relatively low cost
\end{abstract}

CONCLUSIONS: This article emphasises the need for a real metamorphose to all barriers between builders and users which must be abolished so that building and usage become two different parts, of the same planning process.

\section{Introduction}

The sustainable urban development projects realised during these two decades in Albania by the government/municipality have faced problems in the participation and collaboration of actors. Participation is based on voluntary relationships between various actors, which may include government institutions, individual housing and urban services users, community-based organisations, user groups, private enterprises and non-governmental organisations.

There were no clear policies and guidelines developed which can guide the public sector and other partners in the process of forming effective partnerships. This is an indicator which has made the community participation and contribution limited. At the core of democratic development in Albania, stands the need for people to believe that the politician they elected to represent them, are addressing their concerns and best interests in improving the welfare and "quality of life" for the local Community. Nowadays the participatory design processes in Europe are being applied to urban design and planning, as well as to the fields of industrial and information technology. Building together has been described as visionary, strategic planning, and democracy, all aimed in actions that guide in what a community is, what it does, and why it does it [1].

Participation should be justified on the basis of its contribution towards the objectives of urban management. While participation may also serve to broader social and political goals, the decision to employ a participatory approach must in the first place be based on the contribution of this approach towards the goals of housing and urban systems and the effectiveness and efficiency of service delivery. Participation in urban management requires that user communities and responsible institutions have both the capacity and the opportunity for participation. While this may seem self-evident it raises the crucial point that the participation processes have specific requirements in terms of resources, time, and skills; the necessary capacity must be established and adequate opportunities for participation created. And often participation is always associated with the empowerment of the participants.

Citizens who are involved in the planning stages are more willing to get involved in the implementation and monitoring, as well. As a result, trust and understanding of local government processes, community pride, and overall accountability 
are highly increased, enhancing the chances of successful local planning and development [2]

In planning and developing sustainable cities, an involvement of the local communities is required and communities need to analyse their own problems, express their own thoughts to the solutions and support for any community strategies. Focused on the analyses of the legal and administrative context and previous development experiences, the Albanian laws provide avenues for bottom-up participation but between the theory of the law and the actual practice there is often a gap: participation is intended as an invitation to the citizens to express their interests and to comment, but without letting them take part in the plan-making or in its implementation.

Today participation is often synonyms with protest, and is not a step ahead of the decision making process but come next as a reaction [3]. How will become adaptable for the Albanians these new innovative challenges and methods? Why "Participatory design" for Public Building? The main purpose is to provide and ensure a sustainability development for the country and in this context to contribute to Albania's progress, in the framework of the process of European integration.

Professionals are against participation
because it destroys the arcane privileges of
specialisation, unveils the professional secret, strips
bare incompetence, multiples responsibilities and
converts them from private to social [4]. Academics
communities are against it because participation
unfilled all the schemes on which teaching and
research are based. The principal reason for using the
Participatory design is that where the project is
suitable, they can provide better value for living [5].
Citizen participation is a key component in the
educational and social infrastructure building. Citizen
engagement in civic matters provides more responsive
solutions and decisions concerning matters that affect
the entire community.

This article aims to focus on the use of "participatory design" to procure "social infrastructure projects for public building". This paper identifies and compares some characteristics in the development through "participatory design" that supports the principles of context-sensitive design, civil discourse and representative democracy.

\section{Theoretical framework}

Political, economic, social and urban chaotic changes in Albania since the 1990s have dramatically influenced the architecture and urban development. Albania does not have a long history in "participatory development". The effort to promote citizen participation was reflected after ' 90 in various policies and projects that were adopted during that time. Despite the "theoretical" intention by the authorities to enhance participation, in different cities of Albania participation is still inadequate. Involvement of people in the development process usually results in the lack of good will and sustainability of development programs. This often causes the loss of interest in these programs, which in turn increases dependency on government resources.

Participation refers to a process and not a product. What counts, in other words, is not simply the share of Benefits that participants receive, but the role they play in determining the evolution of delivery of urban services in Albania.

The participation depends on voluntary relationships between two or more group's actors, or stakeholders. This implies that the participation is a two-way process; it is concerned not just with the inputs of beneficiaries to a project or program but with the interaction on a continuing basis between beneficiaries, government, and others. Participatory relationships in Albania are voluntary and their effectiveness will depend on each stakeholder being convinced that the process serves their interests.

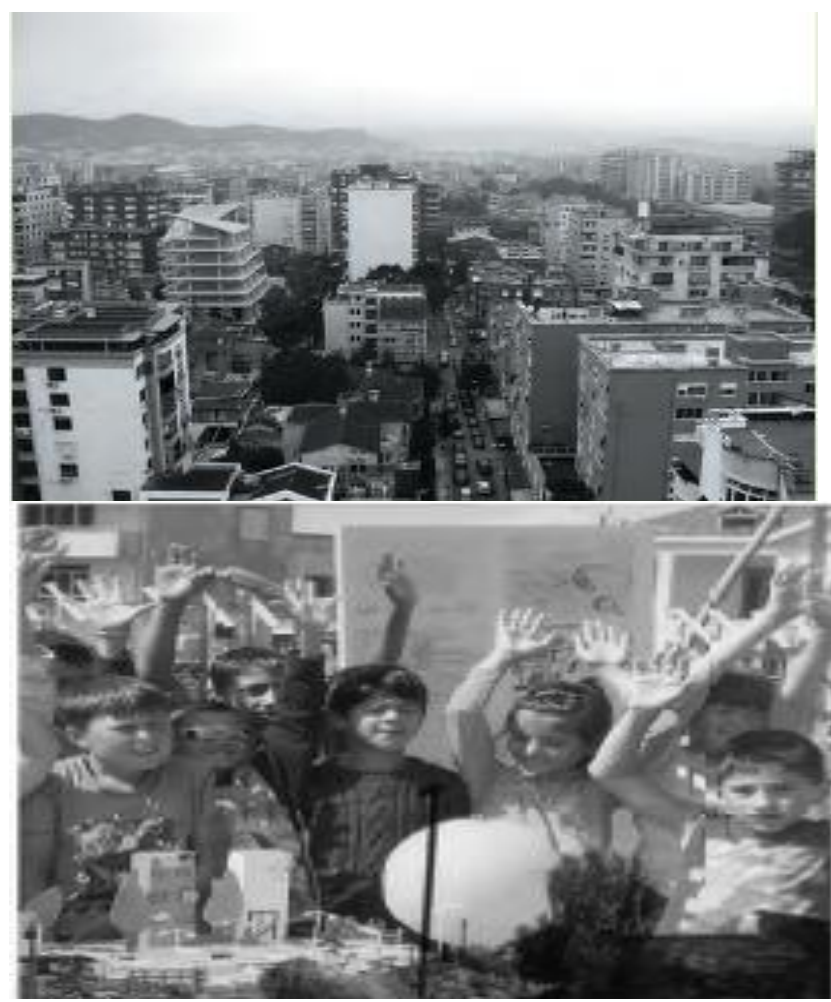

Figure 1: Towards Impacting Policies 2000-2005 (above image), the informal areas people, 2009; (below image). Annual report 2010. Making cities work- Co-PLAN

Several questions should be addressed to make participation more effective, among them to include the capacity of people to participate and their preferences in participation. Experience shows that the philosophy of participatory planning is almost the same 
as in the urban informal to formal. In Albania, people in formal areas are often more reserved and initially hesitate due to distrust that is mainly linked with authority neglecting [6]. Often vulnerable and excluded communities have shown better cooperation than the others. In cases of participation and planning in ethnic groups, they express more enthusiasm and efficiency during the process [6] (Fig. 1). Communities are typical, although not universally, defined on the basis of their geographical foundations, as occupying a particular geographical space [7]. Some communities are homogeneous while others are heterogeneous, and some united while others conflictive. Some communities are governed by leaders chosen democratically who act relatively autonomously from other levels of government, some are governed by leaders imposed from above and represent central [7].

\section{Understanding Participatory Approach}

When people become involved in the design, creation, and maintenance of places, they develop a vested interest in using and maintaining these spaces. When they have a true sense of "ownership" or connection to the places they attend, the community becomes a better place to live, work and visit. The residents' feelings of respect and responsibility for the place bond them to that place and to each other. No architect or town planner can design or build a place that does that.

"The sooner the community becomes involved in the planning process, the better-ideally before any planning has been done," as Kathy Madden and Fred Kent emphasise in the book "How to Turn A Place Around" [8].

"And people should be encouraged to stay involved throughout the improvement effort so that they become owners or stewards of the place as it evolves".

Community involvement in public decision making, especially in transition countries, is too often reactive and negative in character. People are disposed to involve themselves when the status quo is threatened. But citizen involvement is best when community members and grassroots organisations take the lead [9].

In planning and developing sustainable cities, involvement from the local communities is required and communities need to analyse their own problems, express their own thoughts on the solutions and support any community strategies.

The voice of the community in decision-making process is an important requirement to establish the quality products or services that fill their needs and demands. In the field of open space management in Washington, USA, the Interagency Committee for Outdoor Recreation (2005) [10] stated that involving citizens representing diverse community of interests, in all stages (from goal setting to programme and project design) will produce a system that is more responsive to the community's diverse needs. The voice of the community should be taken more seriously since any decision could affect their lives. The public (referring mostly to countries in transition) has the right to know what is happening in the surrounding environment and the right to get involved in the decision-making process which particularly affects them in places where they live and work. There are several methods already initiated by local authorities, planners, managers, the private sectors or even the non-governmental bodies to conduct public meetings as a platform to assess community viewpoints to assist in an urban planning and management process.

\section{Foreign practices in promoting community participation in peri-urban areas}

The analysis and experience of the following survey attempts to help us to reveal some conclusions for the application of community participation in periurban infrastructure.

Community participation in local economic development has been largely limited to consultation. These consultations were, however, crucial to develop demand- driven service product. Sometimes they produced unexpected results which stimulated new ideas.

\section{Minneapolis, Minnesota: Peavey Park, Hope Community}

Hope Community in Minneapolis stimulates the creative base (or juice) of its citizens in shaping and uplifting their community's self-image. The organisation has not only made people believe great things are possible but also it has already accomplished many great things. Through an assetbased community-organizing strategy and "listening process," Hope Community brought people of multiple ethnicities together in small group dialogues. Hope has organised three major listening projects, each including more than three hundred adults and youthfocused on jobs and education, the meaning of community, and the design of a park. The Phillips neighbourhood just south of downtown is the poorest and most racially diverse of Minneapolis's eighty-six neighbourhoods. It serves as home to a long-standing and politically organised Native American community, 
as well as burgeoning Latino and East African immigrant communities. In 1997, Hope began its Listening Project to help learn about residents' ideas on education and jobs. These discussions led to a project to redesign Peavey Park, an underutilised, crime-ridden park that the Minneapolis Park Board had scheduled for an overhaul. The listening and visioning process enabled Hope to engage broad-based participation and to recognise that building community was the central purpose of the park. Hope arrived at the design through a series of creative workshops that were later translated into a formal design and adopted by the Park Board. When complete, this well-designed centre of community activity will signal a massive turnaround for a neighbourhood long infested with drugs, poverty, and hopelessness [10].

\section{Czech Republic, Brno}

Many cities are confronted with the challenge of converting a historically valuable industrial property that is no longer used for its original purpose, and which represents an opportunity to bring in new users. These factories capture people's imagination because they have flexible spaces that can potentially be used for many kinds of activities. However architecturally dramatic they may be, the size and scale of these spaces make it difficult to find new uses for them. In Brno, the Czech Republic, the Vankovka factory, was saved from demolition and designated a historic landmark. An NGO was set up to promote a community-based vision for the complex, an impressive series of industrial halls and loft spaces located adjacent to the historic city centre. The NGO sponsored hundreds of events in the space, making temporary improvements to make the spaces usable. Based on the popular support, the city purchased the factory complex. The former factory is now a thriving shopping centre and events venue, with shops, cafés, and restaurants -- a real destination for the city of Brno [11].

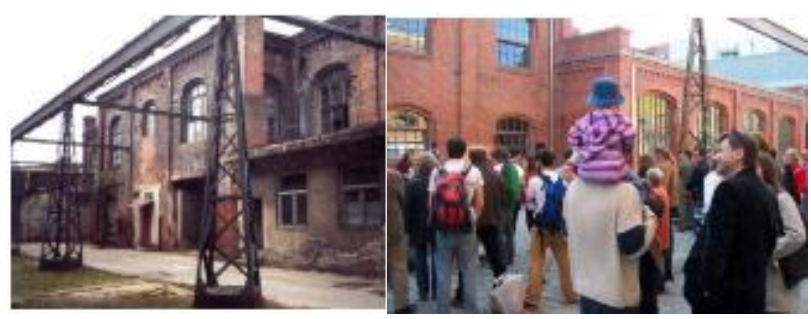

Figure 2: Before and after Vankovka factory

\section{Promoting Equality through Community participation}

Albania is facing difficulties in the adoption of community participation, mainly as a consequence of "legal obstacles". One of the alternatives for a better managing of the actual situation is the project funded by the European Union, which is being implemented simultaneously in Albania, Slovakia, Romania, and the Czech Republic.

The local community in Peri-urban area of Tirana, Allias, is one of the most isolated neighbourhoods of Tirana, confronted with the challenge of converting an industrial property that is no longer used for its original purpose and which represents an opportunity to bring an educational, social and recreational innovative area. Thanks to the support of Eu delegation, were identified educational and social infrastructure, needs, and priorities approached by the Municipality Tirana with concrete plans to cooperate for upgrading the system which transformed in a serious barrier for community integration.

The purpose was to create an area which improves profits and a good lifestyle, of the peri urban area.

The objectives of the project were as follows: 1) Promoting volunteering on local level, increasing awareness on volunteering as one of the ways to civic engagement and its benefits for the entire society, demonstrating municipalities how to encourage volunteering; (2) Encouraging active European citizenship and identity; (3) Collecting and promoting the examples of best practice in the cooperation between the municipalities, civil society organizations and citizens reflecting European democratic values such as common good, rule of law and openness with a special focus on the use of new information and communication technologies as tools for enabling and encouraging civic participation; and (4) To assess the role of local community participation during "listening process', and also organizing small group dialogues for design and construction process.

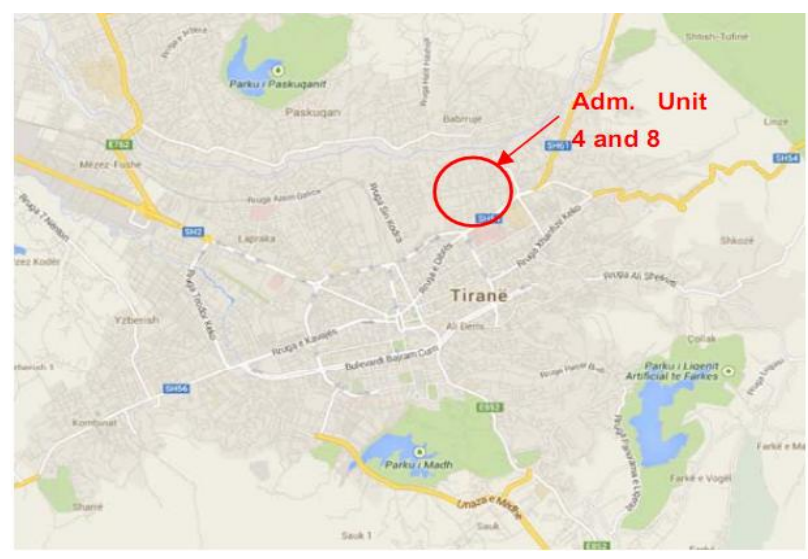

Figure 3: Location of the Administrative Units n. 4 and 8, Tirana

"iC consulted studio", a studio selected by EU delegation in Albania, prepared an analysis and indepth report which identifies the lack of a social community centre and public spaces, recreational 
areas for them and their children to socialise and engage in outdoor activities.

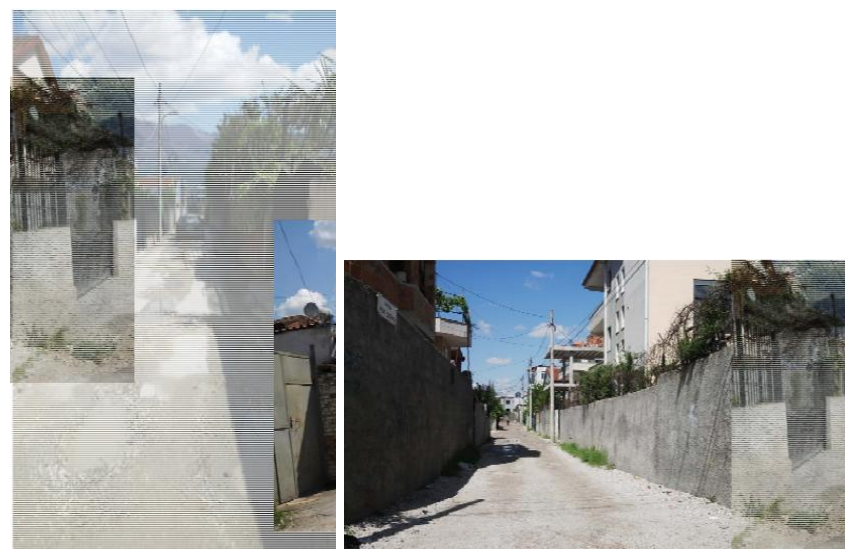

Figure 4: View of some streets from construction area, Tirana

The project is designed to get continuous feedback from stakeholders in this process. Across the administrative areas, which has been part of the journey from the very beginning and has developed a series of public hearings from citizens, architects, engineers and MT's (Tirana Municipality) planners? It is to be appreciated that some of the proposals and suggestions of stakeholders have enriched the project and contributed to refining and implement the idea on the detailed design.

Design prepared by the Consultant relates to the "Construction of Educational, Social Infrastructure for local communities in Tirana" (Figures 3 \& 4).

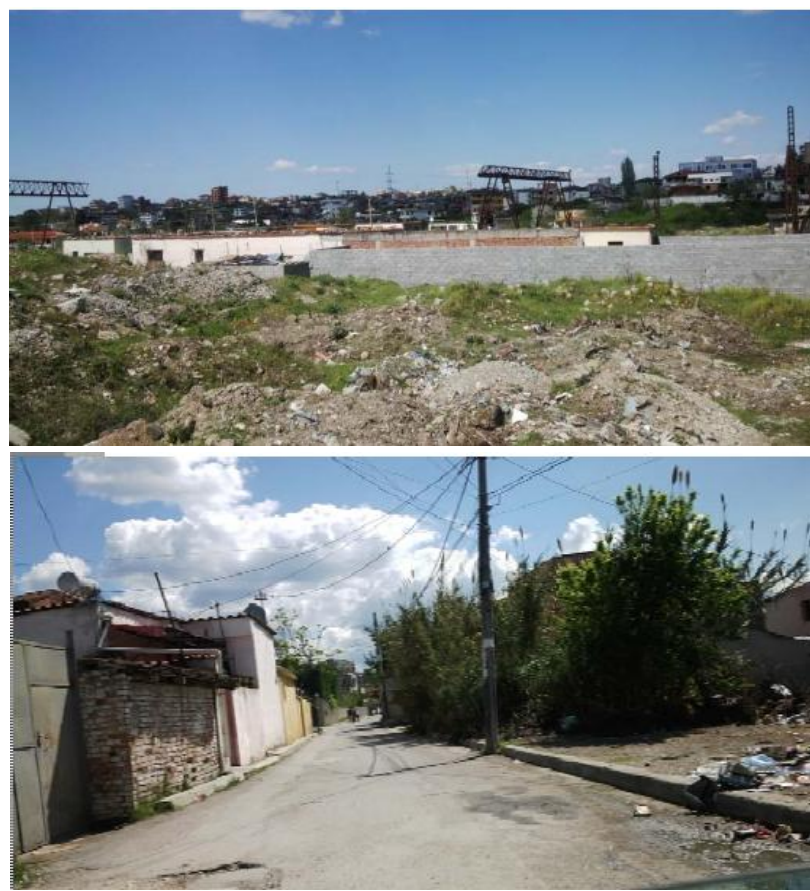

Figure 5: View from building construction area, Tirana

The Partial Urban Planning consists in the construction of a school building of three floors - elementary school, a two-floor nursery daily care/kindergarten and a building of two floors - and in additional Social centre, all located in peri-urban (Allias) area in Tirana city, including sports fields and recreational areas.

In this study, we anticipate participation by consultation for an education and social infrastructure process. This type of participation increases the efficiency in the use of available resources participation and can, for example, help to minimise misunderstanding or possible disagreements and thus time and energy, often spent by professional staff explaining or convincing people of project benefits

The area proposed by Tirana Municipality (administrative Units 4,8 ) lies in the northern suburban quarters of the City bordering with Paskuqan commune. During the socialist system, the area was used as an industrial territory.

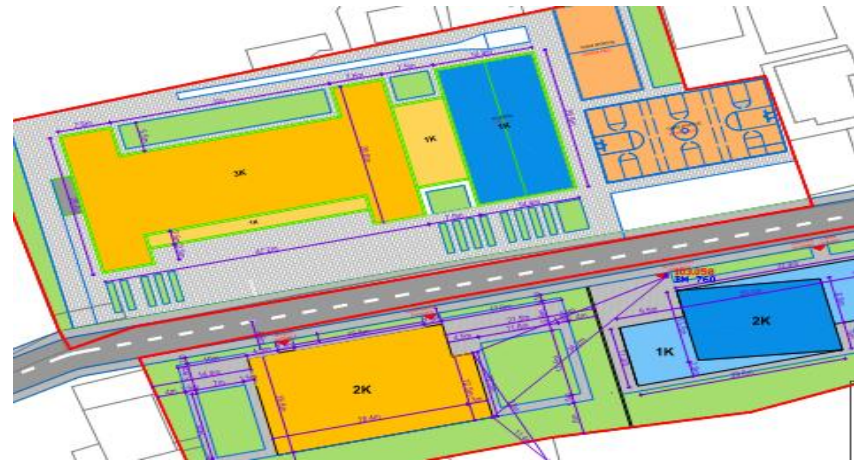

Figure 6: Partial Urban Planning in Tirana, General Plan

By early '90s the area was invaded illegally and became an informal settlement, home to people who migrated from different parts of the country. The population consists in about 16,000 inhabitants. The area is at present not provided with pre-educational facilities and elementary school, lacking social services and related infrastructure including water pipes, sewage network, inner roads and sidewalk in none existent or heavily damaged contributing to the poor living quality of the inhabitants. All education-related service facilities are missing in the area and the nearest one is outside the area, causing an overpopulation at the neighbour school and preeducation facilities where children of these two blocks attend. Therefore the construction of Educational and Social infrastructure for the local community is included under EU-IPA 2012 Local Community Programme for Albania, to provide and achieve some of the educational and public infrastructure facility needs in peri-urban Tirana. Project IPA 2012, financed by the European Union, Delegation in Albania. Contracted price 2,151,159.17 euros, in this context, EU Delegation in Albania in collaboration with the Consultant, provided full support for "Community interest" through public information activities.

They prepared a participation community 
process, through developing series of public hearings with citizens, informal meetings among different ethnic groups; architects, engineers and MT's urban planners; several roundtable discussions, by broadcasting the information in the media, by advisory committees and coordination bodies [12].

In this regard is concluded that participation increases the effectiveness of the project especially in peri - urban areas. People see the project as "theirs" rather than something externally generated. Participation allows these people to have a voice in determining objectives, support project administration and make use of their local knowledge, skills and resources available. Such a consultative process does not concede any share in decision-making and professionals are under obligation to take on board people's views. Participation therefore allows for the more efficient use of the resources available to a project [13].

\section{Findings}

The community vision was to connect the three institutions to each other by improving the public spaces that surrounded and connected them. One of the big things for us, as designers, was to take the focus off the buildings and put it on the things that happen in the spaces between them. The plan, in additional included Community social centre, a working orchard on top of a parking deck, a large screen for projecting movies and digital art, seating, four sports field (2 basketball/ tennis, 2 football fields), creativity areas, creating so "people space" that was long desired. Creativity is becoming one of the most coveted social assets for post - industrial cities with increasingly knowledge-based economies. Gallup \& Knight's Soul of the Community found that: The quality of a place's social offerings was the first factor that people said creates the emotional affinity to their community. Openness to all sorts of people was second. "Our public spaces are perhaps the last vestige of democratic space in our cities" Today we need those kinds of comfortable social environments more than ever. Encouraging creative exploration and experimentation is a great way to develop children's talents and skills.

As Nina Simon quoted: "If you are going to be out in a public space, you have the attitude that this is about connecting to the community that you are in, rather than just trying to figure out how to plug what you do inside the building". When TV was invented, people didn't just say "let's put the radio on the television" they had to re-think the way of programming that was made in order to be successful [14].

\section{Conclusions}

In conclusion, public authorities must follow good examples "related to community participation" as EU Delegation in Albania has promoted in this case study. This visionary model may help in the encouragement civil participation and serve as a model for further collaborative processes between different stakeholders. The problem of participation in Albania is even bigger if we consider the fact that often projects or partial urban planning's starts implementation phase, with a total missing of public information and consultancy.

It is important to foster a cooperative climate and to collaborate with the community in different types of partnerships. Communications must be planned and carried out as an integral part of the management process for any project. A dialogue session between managers or planners and representatives from various community groups is important to know what their needs are and to generate new ideas.

Citizens' participation makes the most effective contribution to local development planning when engaged throughout all the stages of the policy cycle, and not only when the decision-makers find it important. The strengthening and consolidation of successful practices are very important not only for Albania but also for other countries in transition. Community participation in areas of low social cohesion and a low level of popular organisation is a particular challenge. As a conclusion, the community participation in local economic development has been largely limited to consultations and is most important in the areas of service provision and public space development. With regard to the important play role of Local NGOs and Consultants, the investments in community development can be an important contribution to the development of the civil society and the long-term re-orientation of development efforts towards a citizens' rights based approach which include also duties and responsibilities.

A special centre for information interchange should be provided, for the development of contract standards and detailed legal solutions. The transparency must be the main principle for the better management of the project.

Good communication between the local government and the population is necessary and is key to a healthy and participatory democratic political culture.

\section{References}

1. Sanoff $\mathrm{H}$. Community Participation Methods in Design and Planning. John Wiley \& Sons, 2000. 
2. Sanoff H. Participatory Design: Theory \& Techniques. Cornell University, 1990.

3. De Carlo G. An Architecture of Participation. Perspecta. 1980;17:74-79. http://dx.doi.org/10.2307/1567006

4. De Carlo G. 'Architecture's Public', in Architecture and Participation, ed. by Peter Blundell Jones, Doina Petrescu and Jeremy Till. Abingdon: Spon Press, 2007: pp. 3-22.

5. De Carlo G. De Carlo G. II nuovo villaggio Matteotti a Terni: Una esperienza di partecipazione. Casabella. 1977;421:11-35.

6. Co- PLAN. Midis Vakumit dhe Energjise. Co plan 200-2005; 2005- 2009.

7. Schaeffer. School community resources. University of Nebrasca, 1988.

8. Madden K, Kent F. How to turn a place around. Project for Public Spaces, 2000.

9. Borrup T. The creative community builder's handbook: How to transform communities using local assets, art, and culture. Fieldstone Alliance, 2006

10. Archive. Interagency Committee for Outdoor Recreation, USA, 2005.

11. Sýkora L, Ourednek M. Sprawling post-communist metropolis: Commercial and residential suburbanization in Prague and Brno, the Czech Republic. In Employment Deconcentration in European Metropolitan Areas, 2007:209-233.

12. National Programme for Albania under the IPA -Transition Assistance and Institution Building component for the year 2012. EUROPEAN COMMISSION. C(2012) 8208 final, 09.11.2012.

13. Oakley P. Projects with people: The practice of participation in rural development. International Labour Organization, 1991.

14. Simon N. The participatory museum. Museum 2.0, 2010. 